ARTICLE

https://doi.org/10.1057/s41599-019-0336-4

\title{
Metrics for the sustainable development goals: renewable energy and transportation
}

\author{
Jonathan J. Buonocore ${ }^{1 \star}$, Ernani Choma ${ }^{2,3}$, Aleyda H. Villavicencio ${ }^{3}$, John D. Spengler ${ }^{3}$, Dinah A. Koehler ${ }^{4,7}$, \\ John S. Evans ${ }^{3}$, Jos Lelieveld (10 ${ }^{5}$, Piet Klop ${ }^{6} \&$ Ramon Sanchez-Pina ${ }^{3}$
}

\begin{abstract}
The private sector is interested in contributing to the United Nations (UN) Sustainable Development Goals (SDGs); however, they lack credible objective metrics to measure progress, which hinders making a case for financial investing toward the SDGs. A set of science-based metrics could allow corporations and interested investors to meaningfully align their actions with the SDGs in locations around the world where they can make the greatest positive impact. Using existing data on country-level electricity generation and land transportation, we develop a set of simple-to-implement and user-friendly metrics to evaluate the benefits that investments in renewable electricity generation and improvements in land transportation can make toward reducing $\mathrm{CO}_{2}$ and air pollutant emissions and the health impacts of air pollution. We then apply these metrics to a set of renewable electricity companies and find meaningful differences in their progress toward the SDGs on health, energy, and climate. We found that under half of the renewable energy companies in our dataset disclose country-level data on where equipment is being sold, and that there is substantial variability in the $\mathrm{CO}_{2}$ reductions and health benefits of renewable energy based on where these companies have installed capacity. There was not a close statistical relationship between country $\mathrm{CO}_{2}$ emissions rates and country health impact rates, indicating that these metrics cannot serve as good proxies for one another. Future improvements to this methodology should be to implement explicit tracking of air pollution from sources to the locations where it has eventual health impacts, updating the underlying dataset, and improving the degree of detail in emissions inventories. Application of this methodology across the renewable energy sector is limited by the availability of country-level data on where a company has renewable energy capacity installed. The methodology developed here can serve as a basis for better measurement of progress toward climate, energy, and healthrelated SDGs in financial investing and other applications.
\end{abstract}

\footnotetext{
${ }^{1}$ Center for Climate, Health, and the Global Environment, Harvard T.H. Chan School of Public Health, Boston, MA 02115, USA. ${ }^{2}$ Population Health Sciences, Harvard University, Boston, MA 02138, USA. ${ }^{3}$ Department of Environmental Health, Harvard T.H. Chan School of Public Health, Boston, MA 02115, USA. ${ }^{4}$ UBS Asset Management, New York, NY, USA. ${ }^{5}$ Atmospheric Chemistry Department, Max Planck Institute for Chemistry, 55128 Mainz, Germany. ${ }^{6}$ PGGM, Zeist, The Netherlands. ${ }^{7}$ Present address: NetPurpose, London, UK. *email: jbuonocore@mail.harvard.edu
} 


\section{Introduction}

- he United Nations (UN) Sustainable Development Goals (SDGs) are a series of targets set forward in 2015 as part of the UN 2030 Agenda for Sustainable Development to end poverty and ensure prosperity for all people, while protecting the planet and the natural systems on which human society depend (United Nations, 2017; O'Neill et al., 2018; Vörösmarty et al., 2018). There is a substantial gap in investment toward achieving these goals-the UN estimated that the gap for developing countries alone is $\$ 2.5$ trillion per year (United Nations Conference on Trade and Development 2014). In response to this investment gap and a finding that private sector investment has an indispensable role in meeting the SDGs, the UN developed a plan to promote private sector contributions (United Nations Conference on Trade and Development, 2014).

Informed investors can play a critical role in meeting many of the SDGs given both their global reach, and their ability to shape markets and develop new technologies (Vörösmarty et al., 2018). Enhancing investor participation is recognized as an important pathway toward achieving the SDGs, since investors from both the private and public sectors can unleash capital and resources to enhance progress on many SDGs, such as clean water access, clean energy, more efficient transportation, improved health, zero hunger, responsible consumption and production, and climate action (United Nations Conference on Trade and Development, 2014; Vörösmarty et al., 2018).

However, an appeal for private sector investment at this scale will require a higher level of data quality and analysis than what has been in common practice (Vörösmarty et al., 2018; Global Reporting Initiative, 2018; United Nations Conference on Trade and Development, 2014). Specifically, mainstream investors expect and are required by fiduciary duty to deliver market-rate returns (Vörösmarty et al., 2018; Global Reporting Initiative, 2018; United Nations Conference on Trade and Development, 2014). This can best be achieved by investing in more established, publicly-held companies, which tend to have complex global footprints (Vörösmarty et al., 2018; Global Reporting Initiative, 2018; United Nations Conference on Trade and Development, 2014). To attract and retain the interest of large mainstream investors who are committed to both fiduciary duty and making progress toward the SDGs, metrics that credibly link activities of a company to changes in the social and environmental conditions across that global footprint can be extremely helpful (Vörösmarty et al., 2018; Global Reporting Initiative, 2018; United Nations Conference on Trade and Development, 2014). This methodology and system of metrics should be uniform, internally consistent, transparent, match the geographical resolution of financial data that companies often disclose (which is often country-level), and globally applicable to aid in tracking progress that both private and public investors are making toward the SDGs (Vörösmarty et al., 2018). Ideally, these metrics should tie directly to company business models, which are at the core of every investment idea and strategy and the ability of investors to deliver on their fiduciary duty. Furthermore, they should link to the relevant geospatial context of company activity, which is pivotal to the ability of a company to track progress on the SDGs (Vörösmarty et al., 2018; Global Reporting Initiative, 2018; United Nations Conference on Trade and Development, 2014).

To date, there is little in the way of methodologies and metrics that are globally applicable, yet also granular enough to allow aggregation from available data on company activity. No metrics exist that explicitly link company activity, largely from the sale of individual technologies (e.g., wind turbines, solar panels, and more fuel efficient engines for vehicles), to an objective scientific data-driven assessment of how companies are contributing toward the SDGs (Vörösmarty et al., 2018; Global Reporting
Initiative, 2018; United Nations Conference on Trade and Development, 2014). An overview of the existing methodologies is provided in the following section. Having credible methods to measure and track progress toward the SDGs may encourage more investors to get involved, and this may dramatically accelerate progress toward meeting the SDGs (Vörösmarty et al., 2018), (United Nations Conference on Trade and Development, 2014). Credibility may also increase a company's ability and willingness to disclose this information to investors and the public, since these groups may be skeptical of claims from the private sector of a positive contribution toward the SDGs.

Existing sustainability metrics and methods to track progress toward the SDGs. Many groups have sustainability metrics, and corporate sustainability metrics have been proposed and part of annual disclosure practices at many companies. However, these metrics are often focused on environment, society, and governance (ESG) issues, which generally evaluate "bad" behavior of companies, including $\mathrm{CO}_{2}$ emissions, pay inequity, occupational health issues, regulatory enforcement actions, use of resources like land, water, and energy, and many others (Menou and Nishikawa, 2016; Global Reporting Initiative, 2018; Trucost, 2015; Vörösmarty et al., 2018). These ESG metrics generally do not provide insight into the progress that companies are making toward the SDGs (Vörösmarty et al., 2018; Global Reporting Initiative, 2018; Menou and Nishikawa, 2016; Trucost, 2015). This distinction is critically important, since companies that do not make progress toward the SDGs may still perform well based on traditional ESG metrics (e.g., an organic cigarette company).

There are a few frameworks that claim to measure the progress that investments are making toward the SDGs. Many use proprietary metrics and frameworks, or rely on qualitative information (Global Reporting Initiative, 2018). A recent review of corporate environmental performance metrics found inconsistent handling of climate goals, and limited ability to link these metrics to quantitative emissions reductions (Rekker et al., 2019). Some existing approaches use the outputs from a company and use these as a proxy for impact (Vörösmarty et al., 2018). For example, an investor may only look at the amount of renewable energy capacity additions built by a company producing renewable energy or the number of fuel efficient vehicles produced by an automotive manufacturer (Vörösmarty et al., 2018). Some companies may also measure and self-report their outcomes or impacts on certain impact pathways (Global Reporting Initiative 2018; Vörösmarty et al., 2018). The most notable is reporting reductions in $\mathrm{CO}_{2}$ emissions, but companies can also report water use, land use, and other environmental impacts (Vörösmarty et al., 2018; Global Reporting Initiative, 2018). As a consequence, investors end up focusing only on the amount of renewable energy capacity additions built by a company producing renewable energy, the number of fuel efficient vehicles produced by an automotive manufacturer, or the amount of water provided by the activity of a utility company, rather than measurable $\mathrm{CO} 2$ emissions reductions, health improvements, or other forms of measurable progress toward the SDGs (Vörösmarty et al., 2018).

A measurement system focused on outcomes (e.g., renewable energy installed, vehicles on the road) does not explicitly measure progress toward all the relevant SDGs in a way that is explicitly linked to the individual SDG indicators (Vörösmarty et al., 2018; Rekker et al., 2019). For example, a company that only measures and reports $\mathrm{CO}_{2}$ reductions and deployment of renewable energy is tracking its progress toward SDGs 7 (Affordable and Clean Energy), 13 (Climate Action), and 9 (Industry, Innovation, and Infrastructure-which contains $\mathrm{CO}_{2}$ per unit value as an 
indicator). However, this misses the opportunity to report on SDG 3 (Good Health and Well-Being) through air quality improvement, SDGs 6 (Clean Water and Sanitation) and 14 (Life Below Water) through reductions in water consumption, and 6 , 14 , and 15 (Life on Land) through reductions in acid precipitation due to lower $\mathrm{NO}_{\mathrm{x}}$ and $\mathrm{SO}_{2}$ emissions (Buonocore et al., 2015; Buonocore et al., 2016; Millstein et al., 2017; Vörösmarty et al., 2018).

Some measurement methodologies and metrics are available publicly, but only evaluate a limited set of pathways for how their products may have environmental or health benefits (Global Impact Investing Network, 2014). Some private groups-nonprofits, consulting groups, investors, and others-possess methodologies, data, and metrics to estimate the impacts of investments, but the methodological details and underlying data are often not disclosed, making it difficult to evaluate, validate, and compare different methodologies or compare different sectors (Menou and Nishikawa, 2016; Trucost, 2015). Other methodologies link company activity to the SDGs, but do not offer a set of metrics to explicitly measure the progress toward the SDGs or their underlying indicators (Global Reporting Initiative (2016); Impact Management Project, 2018). In addition, for the methods that are publicly disclosed, they commonly use global averages and do not have the capacity to account for differences in the location or other elements of company activity (Vörösmarty et al., 2018; Global Impact Investing Network, 2014). Location and context of these activities is crucially important in determining the actual impact that the activity of a company can have (Vörösmarty et al., 2018; Barbose et al., 2016; Wiser et al., 2017; Millstein et al., 2017; Buonocore et al., 2016; Buonocore et al., 2015).

A set of user-friendly metrics can entice a diverse group of stakeholders-investors, consulting groups, and companies themselves - to get involved and invest in opportunities to make progress on the SDGs, by directly linking company activity to the underlying SDG indicators (Vörösmarty et al., 2018). However, standardized, transparent, and verifiable methodologies to assess positive impacts of companies and their investors are lacking, and these would mitigate the risk of "impact-washing" or "greenwashing"-statements of social or environmental impact lacking a firm basis in evidence (Global Reporting Initiative 2018; Vörösmarty et al., 2018; United Nations Conference on Trade and Development, 2014). Addressing these key concerns may make private sector investors more likely to invest toward the SDGs (Vörösmarty et al., 2018; Global Reporting Initiative, 2018).

Metrics linking SDG 7-affordable and clean energy-to other SDGs. SDG 7-Affordable and Clean Energy-is fundamentally tied to all other SDGs, since it is linked to the achievement of more than half of the targets that underlie the other SDGs (Nerini et al., 2018; McCollum et al., 2018; United Nations, 2018). While some links can require tradeoffs between SDGs, the pursuit of clean energy is expected to help more than hinder progress toward the other SDGs (McCollum et al., 2018; Nerini et al., 2018). Notably, deployment of clean energy aids in addressing climate change and the health impacts from pollution (SDGs 3, 9, and 13), along with providing clean water and sanitation preserving life in water and on land (SDGs 6, 14, and 15) (McCollum et al., 2018; Nerini et al., 2018; United Nations, 2018).

Deploying renewable energy can make progress toward the SDGs, and the progress made by deploying a given amount of renewable energy is dependent on the geographical context (Vörösmarty et al., 2018; Buonocore et al., 2015; Millstein et al., 2017). Methods to better estimate reduced emissions and health benefits of energy companies exist in the peer-reviewed literature
(Vörösmarty et al., 2018; Barbose et al., 2016; Wiser et al., 2017; Millstein et al., 2017; Buonocore et al., 2016; Buonocore et al., 2015), but these methods require fairly precise information on location and amount of renewable energy deployed, and can be resource intensive, which may present a barrier for widespread adoption by the private sector (Vörösmarty et al., 2018). For example, renewable energy has multiple positive impacts, in terms of reducing carbon emissions and improving public health (Vörösmarty et al., 2018; Barbose et al., 2016; Wiser et al., 2017; Millstein et al., 2017; Buonocore et al., 2016; Buonocore et al., 2015). The location and context where the renewable energy is installed is a critical driver of benefits, since location is a major determinant for what other electricity sources are displaced, the emissions rates of these electricity sources, and the populations downwind (Vörösmarty et al., 2018; Barbose et al., 2016; Wiser et al., 2017; Millstein et al., 2017; Buonocore et al., 2016; Buonocore et al., 2015). For example, promoting renewable energy in a location that relies heavily on renewables and hydroelectricity may displace a much smaller amount of carbon emissions than if it was placed in an area with mostly coal-based generation (Barbose et al., 2016; Wiser et al., 2017; Millstein et al., 2017; Buonocore et al., 2016; Buonocore et al., 2015). This will also influence the health benefits from air pollution reduction since emissions, downwind populations, and baseline health can vary dramatically in different locations (Barbose et al., 2016; Wiser et al., 2017; Millstein et al., 2017; Buonocore et al., 2016; Buonocore et al., 2015) (World Bank GroupInstitute for Health Metrics and Evaluation, 2016). While these methodologies do exist and can be used to evaluate the climate and health benefits of the deployment of renewable energy, they can be extremely time and resource intensive to use, require specific information about the location of renewable energy installations that is not publicly reported by the companies, and only exist in a publicly available form for limited geographies (e.g., United States, Canada, European Union, and South Africa). These factors make it difficult to develop a consistent set of metrics using these higher-detail models. That said, an accurate system of metrics to measure progress toward the SDGs that is useful and practical for investing purposes should account for these critical differences in geographical context, without raising barriers to adoption by the investment community (Vörösmarty et al., 2018).

A new set of metrics to track progress toward the SDGs. Here, we develop and present a new framework and methodology that uses deployment of Affordable and Clean Energy-SDG 7-to explicitly measure how progress on SDG 7 consequently makes progress on SDG 3 (Good Health and Well-Being) Target 3.9 "By 2030, substantially reduce the number of deaths and illnesses from hazardous chemicals and air, water and soil pollution and contamination" Indicator 3.9.1 "Mortality rate attributed to household and ambient air pollution" and emissions reductions aligned with SDG 13 (Climate Action) and 9 (Industry, Innovation, and Infrastructure) (United Nations, 2018).

This methodology has the goals of:

- providing an evidence-based method for improving measurement of the progress that companies are making toward the SDGs and their underlying indicators, based on company activity

- combining available data on company activity with earth system and public health science

- being compatible with the types of data and geographical resolution of publicly disclosed corporate data

- advancing methodology for measuring the impact of financial investments

- being transparent, verifiable, and replicable 
- functioning consistently and uniformly for most nations of the globe

- being able to be updated when new data or model results are available

- taking into account differences in the geographical context of company activity, using a simplified method that does not introduce barriers to adoption

while respecting the constraints of:

- ease and simplicity of implementation in the context of financial investing

- ease and simplicity of tracking progress on SDGs by company management

- working with the limited data on corporate activity that is publicly disclosed

- being useful for communicating to all relevant stakeholders

- allowing for use of more complex and resource-intensive methods to estimate impact, if desired

The methodology we develop here provides one path forward to accomplishing these goals, within the existing constraints, for electricity generation and land transportation, and is similar to a methodology used to estimate the benefits of green buildings (MacNaughton et al., 2018). We use publicly available countrylevel data on activity in the electricity generation and land transportation sectors, air pollution emissions, $\mathrm{CO}_{2}$ emissions, and the health impacts of the emissions of the air pollutants to produce country average impact rates for these two different sectors for the year 2010 as a prototypical year. We present these impact rates as metrics to support measurement of the human health benefits, air pollution emission reduction, and climate mitigation, or "impact opportunity", in terms of reduced emissions of $\mathrm{CO}_{2}, \mathrm{SO}_{2}, \mathrm{NO}_{\mathrm{x}}$, and fine particulate matter with a diameter $\leq 2.5 \mu \mathrm{m}\left(\mathrm{PM}_{2.5}\right)$, and health benefits, per either amount of electricity generated, or amount of fuel consumed for land transportation. These metrics more explicitly characterize country-level differences between the rate at which carbon emissions, air pollution reductions, and health impacts of electricity generation will be reduced due to installation of more renewable energy and from improvements in land transportation. We present the degree of heterogeneity in the $\mathrm{CO}_{2}$ emissions rates and the health impact rates of the electricity generation and transportation sectors of each country. In addition, after developing the metrics, we test for statistical relationships between the different metrics at a country-scale to test whether $\mathrm{CO}_{2}$ emissions reductions can be used as a proxy for reductions in the health impacts due to air pollution, effectively collapsing the health impact rate and the $\mathrm{CO}_{2}$ emissions rate into one aggregate index reflecting two types of environmental impact. An index like this could be useful if it has predictive value, since many databases and energy modeling frameworks evaluate $\mathrm{CO}_{2}$ and fuel use, but not other air pollutants. To demonstrate this methodology and the use of the set of metrics, we present results from companies that manufacture wind turbines and utility-scale solar energy technologies. We then evaluate the degree of heterogeneity between different companies, and evaluate the extent to which the location of the activity of these companies drives this variability.

\section{Methods}

Development of impact rate metrics for 2010. To develop the impact rates, we relied on country level data from three different sources using 2010 data, since 2010 is the most recent year for which all necessary data was available. Equations and data sources for each metric are in Table 1. Data on country-level electricity generation, electricity generation fuel mix, and use of fuels for land transportation were taken from the International Energy Agency (IEA) World Energy Statistics and Balances (International Energy Agency, n.d.). Data on vehicle-distance, passenger-distance, or ton-distance traveled is not available globally, so could not be used here. The data on country $\mathrm{CO}_{2}$ emissions rates from electricity generation, and the $\mathrm{CO}_{2}$ emissions from combustion of land transportation fuels was taken from the IEA $\mathrm{CO}_{2}$ Emissions from Fuel Combustion Statistics Database. Total emissions of $\mathrm{NO}_{\mathrm{x}}, \mathrm{SO}_{2}$, and $\mathrm{PM}_{2.5}$ from land transportation and from electricity generation were taken from the Emissions Database for Global Atmospheric Research (EDGAR) (Crippa et al., 2018).

The estimates of total mortality attributed to air pollution by sector were from Lelieveld et al. (Lelieveld et al., 2015), which provided year 2010 estimates of the total health impacts of ambient air pollution by source for each country (Lelieveld et al., 2015). In this study, they estimated the ambient air pollution impacts of major emissions sectors by using emissions data from EDGAR (Crippa et al., 2018; Lelieveld et al., 2015). They then ran these emissions through a high-resolution computational atmospheric chemistry and transport model that estimated air pollution exposures worldwide on an approximate 1.19atitude $\times$ $1.1^{\circ}$ longitude grid from each source sector (Lelieveld et al., 2015). They then geospatially overlaid these air pollution exposures with data on population and population age structure from NASA Socioeconomic Data Center (National Aeronautics and Space Administration; Lelieveld et al., 2015), and mortality data related to five disease categories from the World Health Organization (World Health Organization; Lelieveld et al., 2015), and previously existing estimates of the relationship between air quality and mortality rates from the air pollution epidemiology literature were then used to calculate the health burden of the ambient air pollution exposures output by the computational atmospheric chemistry and transport model (Lelieveld et al., 2015; Crippa et al., 2018; Crippa et al., 2016; Burnett et al., 2014). The basic model framework used by Lelieveld et al. is quite similar to what is used in other air pollution health assessments, including the Global Burden of Disease (Roth et al., 2018), and assessments of cost of air pollution by the World Bank Group (World Bank GroupInstitute for Health Metrics and Evaluation, 2016).

To derive the emissions rates of electrical generation for each country, we divided the total $\mathrm{NO}_{\mathrm{x}}, \mathrm{SO}_{2}$, and $\mathrm{PM}_{2.5}$ emissions from electricity generation from EDGAR by the total electricity generated from the IEA (Table 1). To derive the emissions rates of land transportation for each country, we divided the total $\mathrm{NO}_{\mathrm{x}}$, $\mathrm{SO}_{2}$, and $\mathrm{PM}_{2.5}$ emissions from fuel consumption for land transportation for each country (Table 1). Similarly, to derive the health impact rates due to air pollution from electricity generation for each country, we divided the estimated mortality impacts from electricity generation from Lelieveld et al. (Lelieveld et al., 2015) for each country by the electricity generation in that country from the IEA (Table 1). To derive the mortality impact rates from air pollution from land transportation for each country, we divided the estimated mortality impacts from land transportation for each country by the amount of fuel consumed in land transportation for each country (Table 1).

Statistical tests for correlation between $\mathrm{CO}_{2}$ and health impact of air pollution metrics. After developing the impact rate metrics, we employed a number of linear regressions to test for statistical relationships between $\mathrm{CO}_{2}$ rate and the health impacts rate metric due to air pollution within each sector, and other covariates, including electrical fuel mix and population. We use the test of this correlation to examine the possibility of further 
Table 1 Equations and data sources for country-level impact rate metrics for electricity generation and land transportation.

\begin{tabular}{|c|c|c|}
\hline Metric type & Electricity generation & Land transportation \\
\hline Country average $\mathrm{CO}_{2}$ emissions rate & $\frac{\text { Total } \mathrm{CO}_{2} \text { emissions from electricity (1) }}{\text { Annual electricity generation (1) }}$ & $\frac{\text { Total } \mathrm{CO}_{2} \text { emissions from land transportation (1) }}{\text { Annual fuel consumption in land transportation (1) }}$ \\
\hline Country average $\mathrm{PM}_{2.5}$ emissions rate & $\frac{\text { Total } P M_{2.5} \text { emissions from electricity (2) }}{\text { Annual electricity generation (1) }}$ & $\frac{\text { Total } P M_{2.5} \text { emissions from land transportation (2) }}{\text { Annual fuel consumption in land transportation (1) }}$ \\
\hline Country average $\mathrm{SO}_{2}$ emissions rate & $\frac{\text { Total } \mathrm{SO}_{2} \text { emissions from electricity (2) }}{\text { Annual electricity generation (1) }}$ & $\frac{\text { Total } \mathrm{SO}_{2} \text { emissions from land transportation (2) }}{\text { Annual fuel consumption in land transportation (1) }}$ \\
\hline Country average $\mathrm{NO}_{x}$ emissions rate & $\frac{\text { Total } \mathrm{NO}_{x} \text { emissions from electricity }(2)}{\text { Annual electricity generation }(1)}$ & $\frac{\text { Total } \mathrm{NO}_{x} \text { emissions from land transportation (2) }}{\text { Annual fuel consumption in land transportation (1) }}$ \\
\hline Country average health impact rate & $\frac{\text { Total health burden attributable to electricity (3) }}{\text { Annual electricity generation (1) }}$ & $\frac{\text { Total health burden attributable to land transportation (3) }}{\text { Annual fuel consumption in land transportation (1) }}$ \\
\hline $\begin{array}{l}\text { 1: International Energy Agency. (n.d.) } \\
\text { 2: Crippa et al., } 2018 \\
\text { 3: Lelieveld et al., } 2015\end{array}$ & & \\
\hline
\end{tabular}

simplification or aggregation of these metrics (i.e., can a $\mathrm{CO}_{2}$ emissions rate metric be reliably combined with an air pollution health impact rate into one "impact" index?). This statistical test exclusively tests if there is a relationship between the two metrics. It has no bearing on the internal consistency of each metric independently, and the statistical tests performed do not change the metrics from the values calculated as described in Table 1 and used elsewhere in this manuscript.

Assessing climate, air pollution, and health benefits of selected renewable energy companies. Companies were selected from a set of publicly traded companies who report revenue from renewable energy (FactSet). Each company was categorized by type of renewable energy they are active in-wind, solar, hydroelectricity, and others. Information on total capacity of renewable energy sold or installed globally, by region or country was drawn from publicly available financial reports, investor reports, sustainability reports, and other documentation. For companies that publicly disclose both the amount of capacity installed and the country where it is installed, we applied impact rate metrics to measure the progress of each company toward SDGs 3 (Good Health and Well-Being) and 13 (Climate Action).

Publicly-disclosed data on country-level installed capacity was used to estimate the generation of installed renewable energy capacity using typical capacity factors for each energy technology. Country-level estimates of renewable energy generation were used to calculate the benefits for each country where a company sold its products.

\section{Results}

Impact metrics for electricity generation. There is substantial variation in the $\mathrm{CO}_{2}$ emissions rates of each country's electrical generation, and fairly dramatic variation in the air pollution emission rates and attributable health impacts of each country's electricity generation (Fig. 1a, b). Total $\mathrm{CO}_{2}$ emissions from electricity generation in 2010 ranged from 3.2 billion tons in China to practically zero in 8 countries (Fig. S1) (Lelieveld et al.,
2015). The $\mathrm{CO}_{2}$ emission rates were nearly normally distributed, but the health impact rates were extremely right-skewed (Fig. 2a, Table 2). The $\mathrm{CO}_{2}$ emissions rates ranged from $1300 \mathrm{gCO}_{2} / \mathrm{kWh}$ in Kosovo, where the grid is largely powered by coal, to near zero $\mathrm{gCO}_{2} / \mathrm{kWh}$ in Paraguay, where nearly all electricity generation is from hydropower (Table 2). Total health impacts from electricity generation in 2010 ranges from 240,000 per year in China to practically zero in 11 countries (Fig. S3) (Lelieveld et al., 2015). The health impact rates from generation ranged from 350 deaths/ TWh in Myanmar, to near zero in eleven countries (Table 2). The global average impact of all countries, weighted by each country's total electricity generation, was $530 \mathrm{gCO}_{2} / \mathrm{kWh}$ and 22 mortality cases per TWh, the medians were $440 \mathrm{gCO}_{2} / \mathrm{kWh}$ and 5.7 deaths per TWh (Table 2). The emission rates for $\mathrm{SO}_{2}, \mathrm{NO}_{\mathrm{x}}$, and $\mathrm{PM}_{2.5}$ are also right-skewed, and each showed substantial variation between countries. For $\mathrm{PM}_{2.5}, \mathrm{NO}_{\mathrm{x}}$, and $\mathrm{SO}_{2}$ emission rates, and the health impacts outcomes, the generation-weighted mean is lower than the equally-weighted mean, indicating that the emission rates are relatively higher in countries with lower total generation.

Relationship between impact rate metrics for electricity generation. As expected, the $\mathrm{CO}_{2}$ emission rate predicts the health impact rate somewhat poorly (model adjusted $r^{2}=0.24$ ), but the model with $\mathrm{CO}_{2}$ emission rate, country population, and their interaction term (the product of the $\mathrm{CO}_{2}$ emission rate and population) performs substantially better (model adjusted $r^{2}=0.56$ ) (Table 3). Model 3, testing the interaction between population and both $\mathrm{CO}_{2}$ emissions rate and individual terms for the percentage of generation from coal, oil, and gas, performs even better (model adjusted $r^{2}=0.603$ ). However, model 4, testing the grid mix independent of population performs less well (model adjusted $r^{2}=0.523$ ), with the independent grid mix terms not being significant. Based on the fairly low $r^{2}$ values for these models, we decided not to further simplify these metrics. This indicates that countries with high $\mathrm{CO}_{2}$ emissions rates for a sector are not the same as those with a high health impact rate, so 

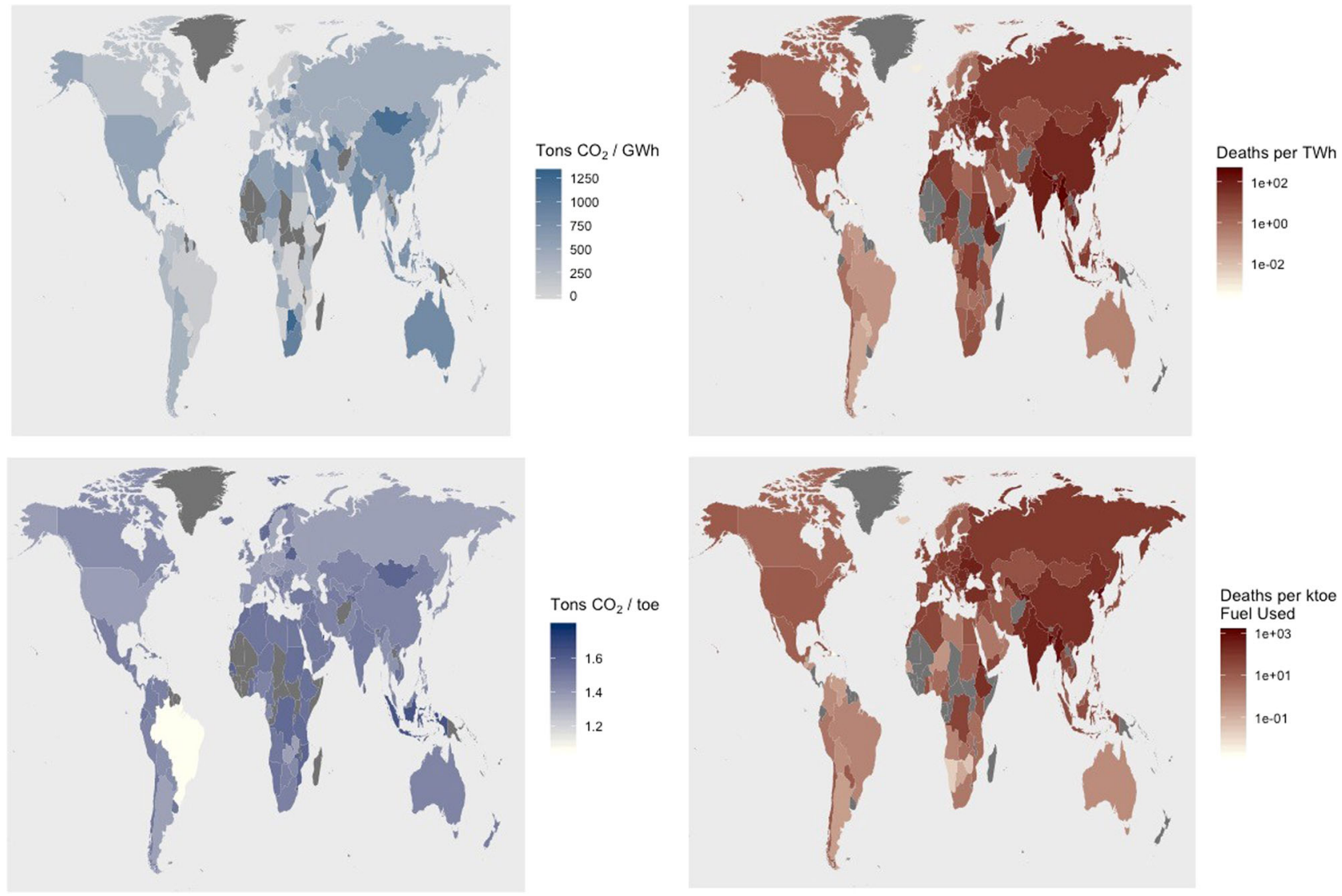

Fig. 1 Carbon dioxide emission rates (Tons per GWh) of each country's electrical grid, health impact rate (excess mortality cases per TWh) of air pollutant emissions from each country's electrical grid, $\mathrm{CO}_{2}$ emissions rate (Tons $\mathrm{CO}_{2}$ per ton of oil equivalent) from transportation in each country, and health impact rate (deaths per 1000 tons of oil equivalent consumed) from air pollutants from transportation in each country, in 2010 (International Energy Agency, n.d.). Countries in dark gray did not have data available.

combining metrics into one aggregated "impact" index would not result in a reliable index.

Impact opportunity metrics for transportation. There is much less variability in the $\mathrm{CO}_{2}$ emission rate and the attributable health impacts from fuels used for land transportation than for electricity generation (Fig. $1 \mathrm{c}$, d). Total annual $\mathrm{CO}_{2}$ emissions ranged from 1.5 billion tons in the U.S. to 0.1 million tons in Eritrea (Fig. S2). Total health impacts in terms of annual mortality cases from land transportation ranged from 45,000 in China to practically zero in 13 countries (S4) (Lelieveld et al., 2015). The $\mathrm{CO}_{2}$ emission rates are reasonably normally distributed, but the health impact rate is right-skewed (Table 4, Fig. 2b). Health impact rates per ton fuel consumed ranged from practically zero in 13 countries, to 1200 deaths per ton of oil equivalent (toe) in North Korea. The $\mathrm{CO}_{2}$ emissions rates ranged from 1.06 tons $\mathrm{CO}_{2}$ /toe in Pakistan, to 1.78 tons $\mathrm{CO}_{2} /$ toe in Armenia. The consumption-weighted mean $\mathrm{CO}_{2}$ emissions rate is higher than the equally-weighted mean, and the consumption-weighted health impact rate is lower than the equally-weighted mean, indicating that the mean health impact is comparatively higher in low-consuming countries, but the $\mathrm{CO}_{2}$ emission rate is relatively low. The emission rates of $\mathrm{SO}_{2}, \mathrm{NO}_{\mathrm{x}}$, and $\mathrm{PM}_{2.5}$ from land transportation are also right-skewed, but less so than for electricity generation.

Renewable energy company data disclosure patterns. The set of renewable energy companies contained 11 companies, 7 in wind, and 4 in solar, that reported renewable energy operations (Table 5).
Of the initial set of companies, 8 (5 wind, 3 solar) published sustainability reports. Of the initial set of 11 companies, there was some information on installed capacity available in either the annual report or the sustainability report for 8 companies (6 wind, and 2 solar) in reporting for 2015, 2016, or 2017. Of those 8 companies, 6 ( 4 wind, 2 solar) had an explicit mention of the total capacity installed globally; and of those 6 companies, 5 (4 wind, 1 solar) had explicit information on installed capacity, with country-level detail (Table 5).

Benefits of renewable energy companies. The five companies that explicitly reported country-level data on new installed capacity, installed in total $21,000 \mathrm{MW}$ of additional renewable energy capacity in one year. This was estimated to generate over $57,000 \mathrm{GWh}$ of renewable energy per year (Table 6). In total, this additional renewable energy capacity installed that year would result in a total of 29 million tons of $\mathrm{CO}_{2}$ not being emitted into the atmosphere, and 1200 lives saved as a result of reductions in $\mathrm{PM}_{2.5}, \mathrm{NO}_{\mathrm{x}}$, and $\mathrm{SO}_{2}$ emissions (Table 6). Company activity did vary, and the estimated absolute $\mathrm{CO}_{2}$ reduction and lives saved, along with the rates of $\mathrm{CO}_{2}$ reduction and health benefits per both MW installed capacity and amount of electricity generated, varied substantially between companies, although this variability was much more pronounced for the health benefits rather than the climate benefits (Table 6).

The main driver for the variability between companies was the location of their activity. Companies active in countries with high $\mathrm{CO}_{2}$ emissions rates, or countries with high health impacts from electrical generation, tended to have much higher benefits that 


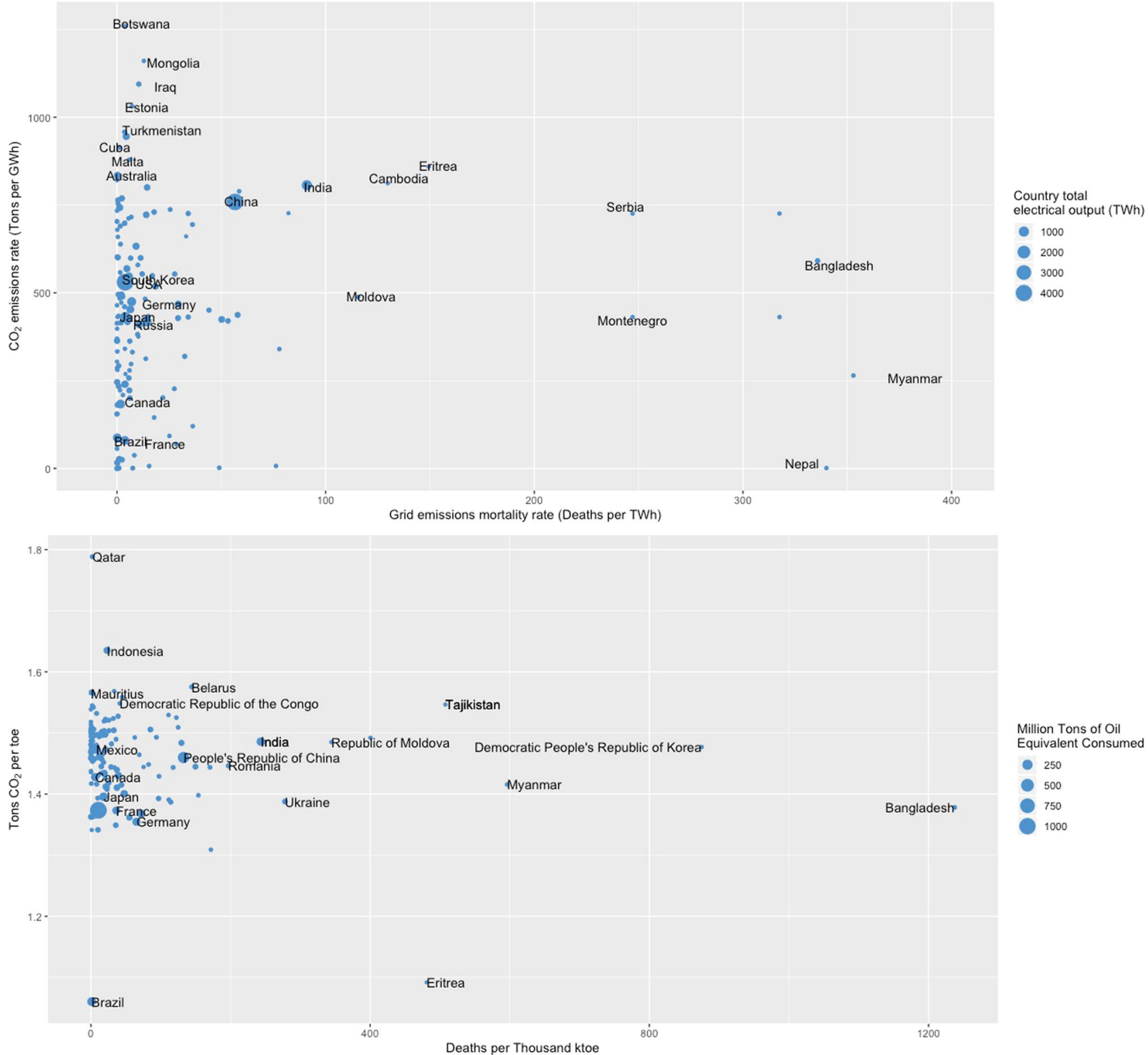

Fig. 2 Health impacts due to air pollution and $\mathrm{CO}_{2}$ emissions rate (International Energy Agency, n.d.), along with energy consumption for electricity generation and land-based transportation in 2010.

Table 2 Emissions rates and health impact rate of country generation.

\begin{tabular}{|c|c|c|c|c|c|}
\hline & $\mathrm{CO}_{2}(\mathrm{~g} / \mathrm{kWh})$ & $\mathrm{PM}_{2.5}(\mathrm{mg} / \mathrm{kWh})$ & $\mathrm{SO}_{2}(\mathrm{mg} / \mathrm{kWh})$ & $\mathrm{NO}_{\mathrm{x}}(\mathrm{mg} / \mathrm{kWh})$ & Health impact rate (deaths / TWh) \\
\hline Mean & 460 & 160 & 4800 & 2800 & 31 \\
\hline Total generation-weighted mean & 530 & 112 & 1900 & 1300 & 22 \\
\hline Median & 440 & 27 & 1900 & 1600 & 5.7 \\
\hline
\end{tabular}

those that were more active in areas with low health impacts or $\mathrm{CO}_{2}$ emissions rates from electrical generation. Wind Company $\mathrm{C}$ saves close to 250 lives per 1000 additional MW of wind energy, whereas Wind Company B and Wind Company D both save 25 lives per 1000 new MW installed (Table 6). This is largely because Wind Company $\mathrm{C}$ is mainly active in India (Fig. 3b), which has an electrical grid with a very high impact rate, whereas $\mathrm{B}$ and $\mathrm{D}$ are largely active in North America and Europe, where the impact rates of the underlying grids are lower (Fig. 3a, c). Wind Company
A is in between the two, since they are active in China and India (Fig. 3d). The example of Wind Company A demonstrates the effect of geography quite clearly-there are similar levels of new wind installation in both China and the USA, but much higher health benefits in China because the background grid has a much higher health impact rate (Fig. 3d). Solar Company A shows this similarly-despite having much more installed capacity in the USA, there is greater health benefit in China and India from a much smaller amount of installed capacity (Fig. 3e). 
Table 3 Regression model results relating the health impact rate from electrical generation (deaths/TWh) to electricity $\mathrm{CO}_{2}$ emissions rate.

Model 1:

Mortality rate $=\mathrm{CO}_{2}$ emissions rate

\begin{tabular}{lllrr} 
& Estimate & Std. error & $\boldsymbol{t}$ value & Pr $(>|\mathbf{t}|)$ \\
\hline (Intercept) & -16.2 & 6.09 & -2.67 & 0.00848 \\
$\mathrm{CO}_{2}$ emissions rate & 0.0716 & 0.0106 & 6.75 & $3.73 \mathrm{E}-10$ \\
Model $\mathrm{r} 2=0.243$ & & &
\end{tabular}

Model 2:

Mortality rate $=\mathrm{CO}_{2}$ emissions rate $\times$ population

\begin{tabular}{|c|c|c|c|c|}
\hline & \\
\hline & Estimate & Std. error & $t$ value & $\operatorname{Pr}(>|t|)$ \\
\hline (Intercept) & $1.55 \mathrm{E}+01$ & $6.06 \mathrm{E}+00$ & 2.55 & 0.0118 \\
\hline Population & $-1.74 \mathrm{E}-04$ & $4.43 E-05$ & -3.93 & 0.000137 \\
\hline $\mathrm{CO}_{2}$ emissions rate & $-3.19 \mathrm{E}-03$ & $1.09 \mathrm{E}-02$ & -0.29 & 0.77 \\
\hline Population: $\mathrm{CO}_{2}$ emissions rate & $2.77 \mathrm{E}-07$ & $5.72 \mathrm{E}-08$ & 4.84 & $3.56 \mathrm{E}-06$ \\
\hline
\end{tabular}

Model $\mathrm{r} 2=0.564$

Model 3:

Health burden rate $=$ Population $\times\left(\mathrm{CO}_{2}\right.$ emissions rate $+\%$ coal $+\%$ oil $+\%$ natural gas $)$

\begin{tabular}{|c|c|c|c|c|}
\hline & & & & \\
\hline & Estimate & Std. error & $t$ value & $\operatorname{Pr}(>|t|)$ \\
\hline (Intercept) & $8.15 \mathrm{E}+00$ & $3.00 \mathrm{E}+00$ & 2.713 & 0.00754 \\
\hline Population: $\mathrm{CO}_{2}$ emissions rate & $5.94 \mathrm{E}-07$ & $1.13 \mathrm{E}-07$ & 5.269 & $5.29 E-07$ \\
\hline Population: \% coal & $-5.29 \mathrm{E}-02$ & $1.10 E-02$ & -4.805 & $4.05 E-06$ \\
\hline Population: \% natural gas & $-2.53 E-02$ & $9.02 \mathrm{E}-03$ & -2.81 & 0.00569 \\
\hline Model 4: & \multicolumn{4}{|c|}{ Health burden rate $=$ Population $\times\left(\mathrm{CO}_{2}\right.$ emissions rate $)+\%$ coal $+\%$ oil $+\%$ natural gas } \\
\hline (Intercept) & $3.48 \mathrm{E}+00$ & $5.84 \mathrm{E}+00$ & 0.596 & 0.552 \\
\hline$\%$ coal & $-8.27 \mathrm{E}+02$ & $1.15 \mathrm{E}+03$ & -0.72 & 0.473 \\
\hline$\%$ oil & $-8.97 \mathrm{E}+02$ & $2.00 \mathrm{E}+03$ & -0.45 & 0.654 \\
\hline$\%$ natural gas & $1.56 \mathrm{E}+03$ & $1.08 \mathrm{E}+03$ & 1.437 & 0.153 \\
\hline $\begin{array}{l}\text { Population: } \mathrm{CO}_{2} \text { emissions rate } \\
\text { Model r2: } 0.523\end{array}$ & $6.37 \mathrm{E}-08$ & $7.02 \mathrm{E}-09$ & 9.075 & $1.20 \mathrm{E}-15$ \\
\hline
\end{tabular}

Table 4 Emissions rates and health impact rate of land-based transportation by country, in terms of tons of oil equivalent (toe), a unit based on the energy content of different fuels.

\begin{tabular}{llllll} 
& $\mathbf{C O}_{\mathbf{2}}$ (tons $\mathbf{C O}_{\mathbf{2}}$ /toe) & $\mathbf{P M}_{\mathbf{2 . 5}} \mathbf{( k g / t o e )}$ & $\mathbf{S O}_{\mathbf{2}}$ (kg/toe) & $\mathbf{N O}_{\mathbf{x}} \mathbf{( k g / t o e )}$ & Health impact rate (deaths / 1000 toe) \\
\hline Mean & 1.46 & 0.82 & 20 & 11 & 67 \\
Consumption-weighted mean & 1.40 & 0.77 & 13 & 8.7 & 44 \\
Median & 1.47 & 0.088 & 7.8 & 7.4 & 17 \\
Range & $1.06-1.78$ & $0.00006-26$ & $0.0001-450$ & $0.018-92$ & $0-1200$ \\
\hline
\end{tabular}

Table 5 Disclosure patterns of renewable energy companies.

\begin{tabular}{llll} 
Question & $\begin{array}{l}\text { Number of all companies } \\
\text { (\%, of 11) }\end{array}$ & $\begin{array}{l}\text { Number of wind companies } \\
\text { (\%, of 7) }\end{array}$ & $\begin{array}{l}\text { Number of solar companies } \\
\text { (\%, of 4) }\end{array}$ \\
\hline $\begin{array}{l}\text { Has published annual report? } \\
\text { Has published sustainability report? }\end{array}$ & $11(100 \%)$ & $7(100 \%)$ & $4(100 \%)$ \\
$\begin{array}{l}\text { Annual report or sustainability report contains some } \\
\text { information on installed capacity? }\end{array}$ & $8(73 \%)$ & $5(71 \%)$ & $3(75 \%)$ \\
$\begin{array}{l}\text { Annual report or sustainability report contains explicit } \\
\text { mention of total global installed capacity? }\end{array}$ & $6(53 \%)$ & $6(86 \%)$ & $2(50 \%)$ \\
$\begin{array}{l}\text { Annual report or sustainability report contains explicit } \\
\text { mention of installed capacity, by country? }\end{array}$ & $5(45 \%)$ & $4(57 \%)$ & $2(50 \%)$ \\
\end{tabular}

\section{Discussion}

The country-level metrics reveal dramatic variability in the rates of impact for both electricity generation and land transportation, and that the relationship between $\mathrm{CO}_{2}$ reductions, air pollutant reductions, and health benefits has meaningful differences across countries. The degree of variability in electricity generation is wider than it is for transportation. For electricity generation, some countries have practically zero impact-both in terms of $\mathrm{CO}_{2}$ emissions and health outcomes from electricity generation, while others are extremely high-around 350 excess deaths and 
Table 6 Benefits of companies by year (blinded company names provided).

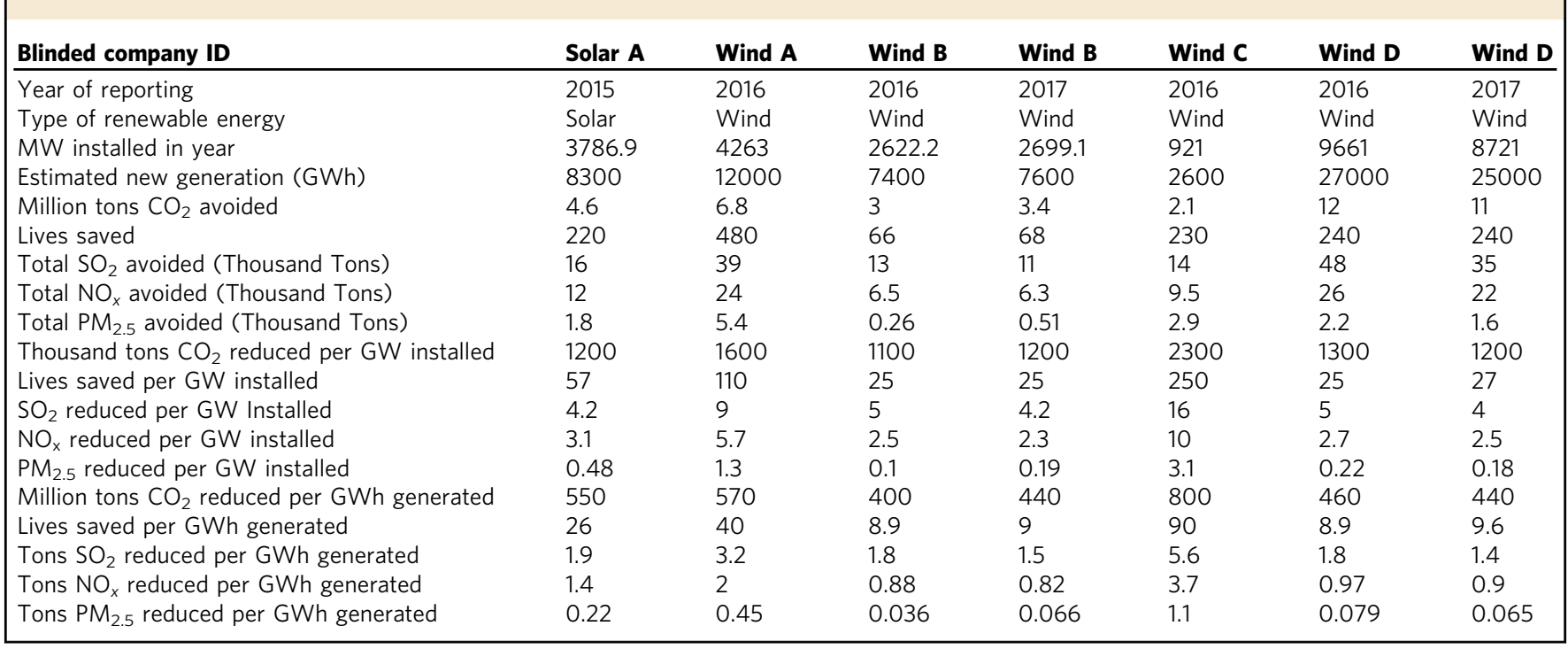

1.3 million tons $\mathrm{CO}_{2}$ per TWh of electricity generated. There is variability in transportation, to a lesser degree than there is for electricity. This is partially from the electricity impact rates aggregating a wide variety of fuel types, including coal, gas, oil, solar, hydro, nuclear, and others, while transportation impacts are based on units of fuel consumed, which is largely gasoline (Fig. 4). The comparative difference between the consumption-weighted and equally-weighted mean health impact rates for electricity generation indicates that the health impact rates are more heavily driven by countries producing large amounts of electricity than $\mathrm{CO}_{2}$ emissions rates.

The variability in the health impact rates reflects the importance of location and other contextual factors in determining the opportunity for benefits from investments in the energy and transportation sectors. The differences between countries in the impact rates of electrical generation are related to a number of geographical and contextual factors. These include: (1) differences in population density and baseline health of populations downwind of pollution sources, (2) the spatial relationship between these populations and high-emitting electrical generation sources within a country, and (3) differences in meteorology, topology, and other factors that mediate population exposure to air pollutant emissions from these sources. The differences in emission rates for electricity production reflect differences in the generation mix, quality of fuels used, and the presence and use of pollution controls. Countries like India and Poland, with large populations near high emitting electricity generation sources, such as coal-fired power plants that use low-quality fuel and have little or no pollution control devices, will have much higher rates of health impact from electricity generation than countries like Iceland or Norway, which generates most of their electricity from hydropower, wind, solar, and geothermal sources. Similarly, the variability in transportation impact rates is due to the spatial relationship between sources and high population centers, and variation in the emission rates due to differences in the vehicle fleet. The results of the statistical analysis of the impact metrics indicate, as expected, that further simplification of this framework would eliminate important distinctions between countries due to these factors, and that $\mathrm{CO}_{2}$ emissions alone is not adequate to act as a proxy for health impacts.

The application of this model to renewable energy demonstrates that renewable energy companies are making substantial progress toward SDG 13-climate action, 9-industry, innovation, and infrastructure, and SDG 3-good health and well-being. However, this methodology reveals meaningful differences between companies in progress toward SDGs 13 and 3, largely due to underlying variability in the countries where these companies are active. For many companies, the amount of progress toward SDGs is highly determined by the locations where they are installing renewable energy, and the fact that $\mathrm{CO}_{2}$ reductions do not necessarily occur at the same rate as health benefits. This is illustrated by comparing wind companies $\mathrm{C}$ and $\mathrm{D}$, where wind company $\mathrm{D}$ has installed nearly 10 times as much new capacity as wind company C. Despite this, company D avoids only 5 times as much $\mathrm{CO}_{2}$ emissions as company $\mathrm{C}$, and the companies have nearly the same health benefits. Solar company A reduces the same amount of $\mathrm{CO}_{2}$ per $\mathrm{MW}$ installed as wind company $\mathrm{B}$, but extends over twice as many lives per MW installed. Wind company B has similar health benefits per MW installed to wind company $\mathrm{D}$, despite wind company $\mathrm{D}$ avoiding reducing more of the air pollutants $\mathrm{SO}_{2}, \mathrm{NO}_{\mathrm{x}}$, and $\mathrm{PM}_{2.5}$ per $\mathrm{MW}$ than wind company $\mathrm{B}$. The fact that different companies within the same sector are making different rates of progress toward the SDGs also demonstrates the information that can be gained from public data disclosure.

The regression results for the impact rate metrics for electricity generation did reveal the expected trend that health impacts are higher in countries with both large populations and high $\mathrm{CO}_{2}$ emissions rates, and that both components are necessary for a grid to have high health impact rate. The inclusion of additional factors, such as fuel mix in the models provided minimal improvements in model performance, and in some cases, resulted in model coefficients that were counterintuitive or difficult to interpret in a manner consistent with known mechanisms of energy use, emissions, exposure, and health outcomes. This is not very surprising - the ability for changes to existing transportation and electricity generation networks to have benefit is driven by the emissions rates of different sources, the geographical relationship between these air pollution sources and areas with high population (Buonocore et al., 2015; Buonocore et al., 2016; Driscoll et al., 2015; Buonocore et al., 2014), and other contextual factors which are not explicitly represented in this simplified statistical model. These results indicate that there is value in having separate metrics for $\mathrm{CO}_{2}$ reductions, air pollution reductions, and health benefits, and in basing the health benefits on an atmospheric chemistry and transport model. Further 

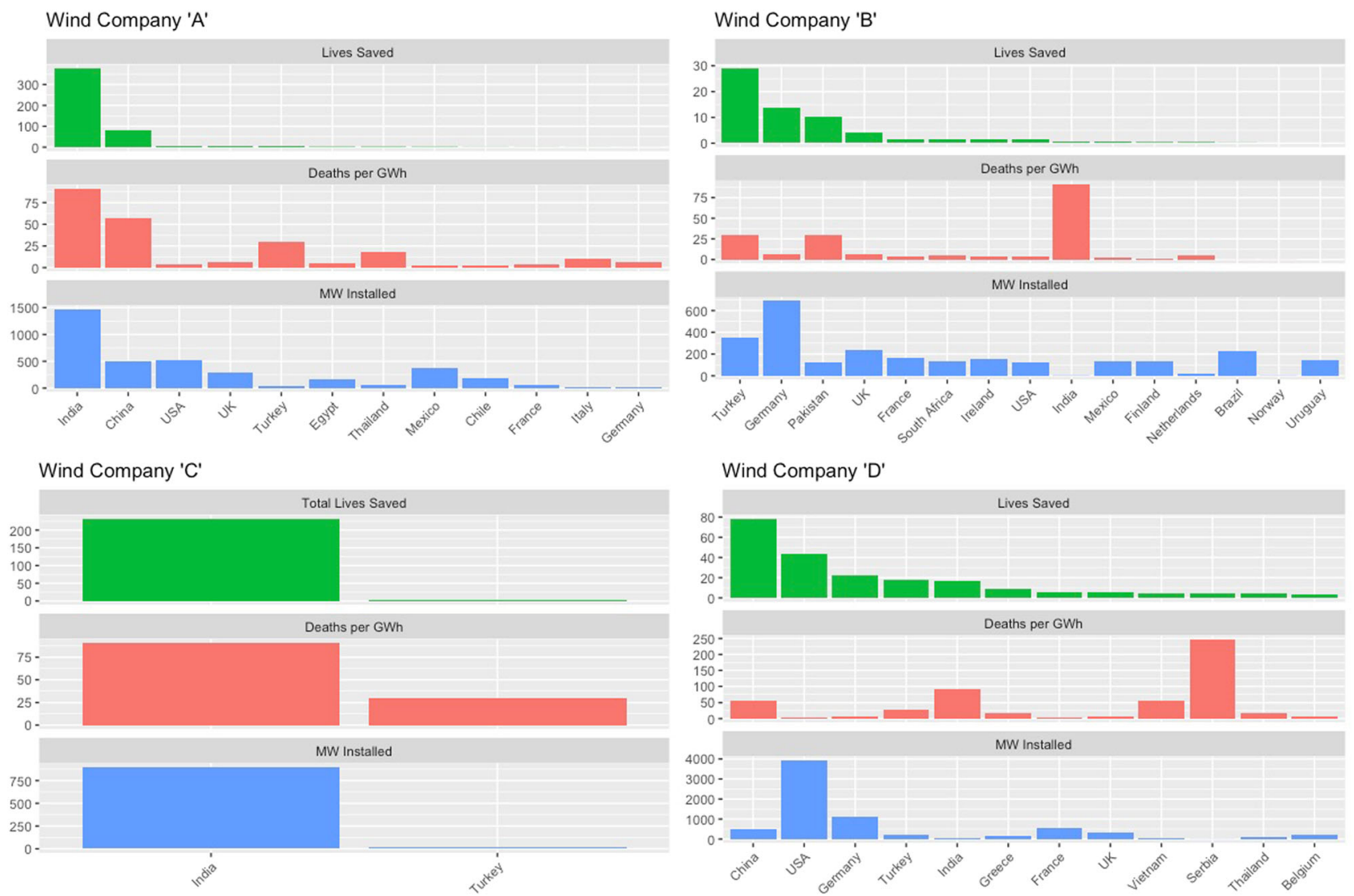

Solar Company 'A'

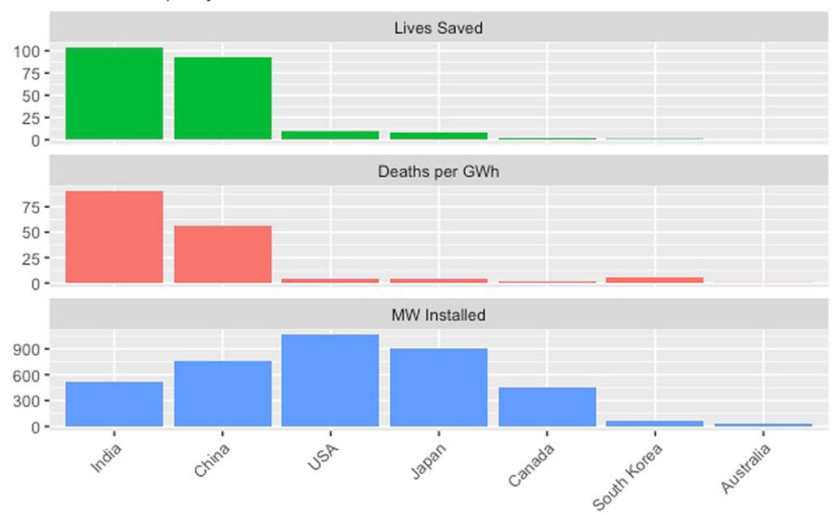

Fig. 3 Installed capacity, electrical generation health impact rate, and total lives saved for four wind energy companies and one solar energy in 2010.

simplification of these metrics, or using one outcome as a proxy for another, would result in important information being lost, and the metrics losing their ability to reveal differences between companies.

Limitations of country-level model. The modeling framework for air pollution has some limitations, related to allocation of trans-boundary air pollution, geographic specificity, treatment of time, and aggregation of different source types, each of which is described below. Applying these metrics to publicly disclosed data on renewable energy installed by companies can introduce a number of sources of uncertainty and bias. The expected direction, magnitude, and methods to reduce uncertainty and bias are summarized in Table 7. This model assigns health impacts to the country in which the health impacts are occurring, not the country that is the source of the air pollution, since the air pollution model did not incorporate source tracking (Lelieveld et al., 2015). This can result in impact estimates for some countries that cannot be easily explained by their power plant or transportation fleet composition, air pollution emissions, meteorology, and population distribution, especially smaller ones. For example, in this model, Nepal has a fairly high impact rate assigned to it for electricity generation. However, Nepal relies predominately on hydropower, which does not directly emit air pollution. Therefore, the impact rate for electricity generation in Nepal should be near zero, but the model assigns it a fairly high value, related to air pollution transport from India. For another example, other studies have found impacts of emissions of air pollutants from China that can impact air quality in the U.S. (Lin et al., 2017; Lin et al., 2014), indicating in our model that some of the impacts from air pollution in the U.S. originates from other countries upwind. Our results are also dependent on the Integrated Exposure Response (IER) function from the Global Burden 


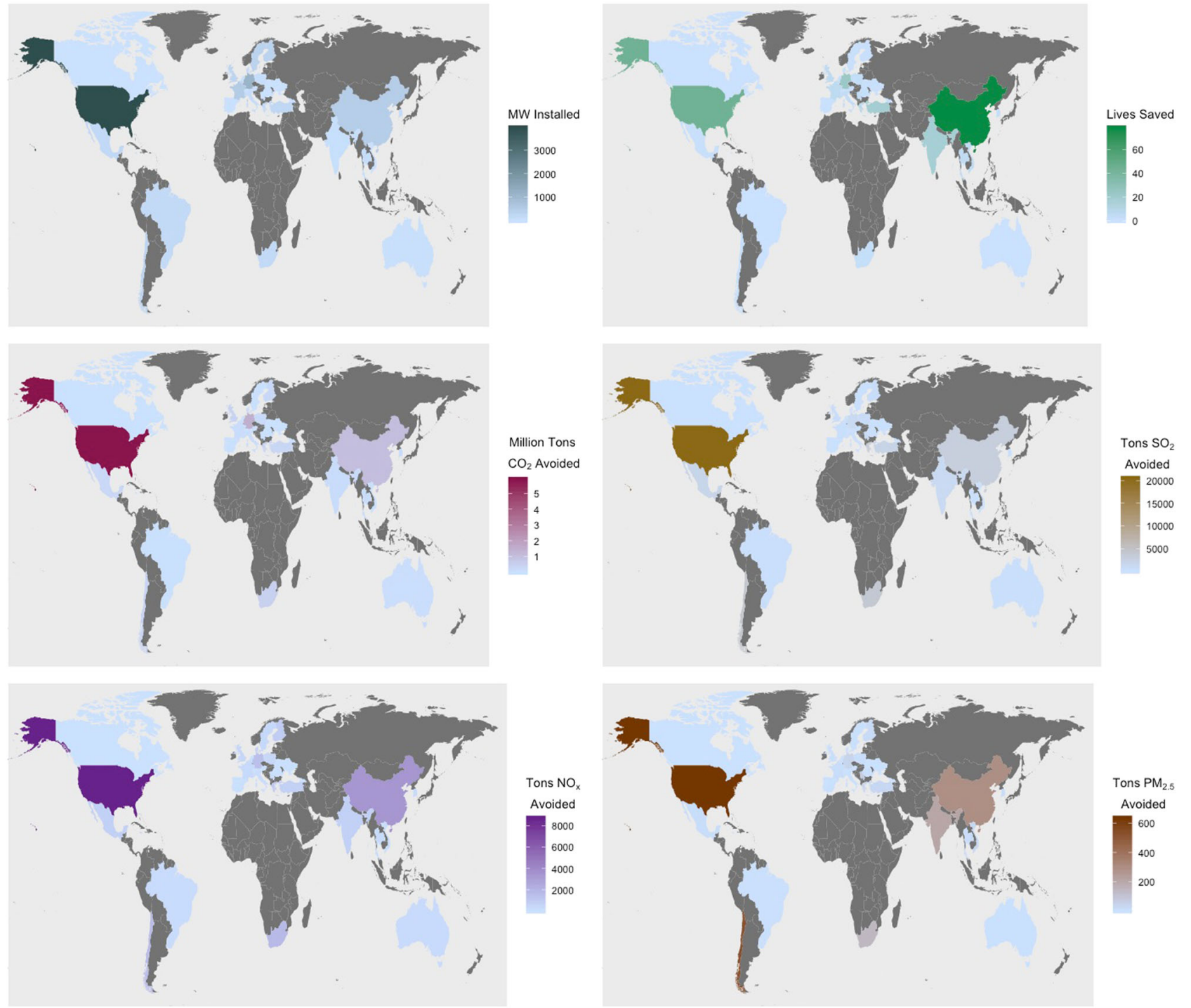

Fig. 4 Installed capacity, lives saved per year, million tons of $\mathrm{CO}_{2}$ avoided, and tons of $\mathrm{SO}_{2}, \mathrm{NO}_{\mathrm{x}}$ and $\mathrm{PM} 2.5$ avoided by Wind Company $\mathrm{D}$ in 2010 .

\section{Table 7 Model biases.}

\section{Source of uncertainty/bias}

electrical grid

Does not account for trans-boundary pollution (health only)

Same capacity factor applied across all installations

Does not account for individual power plants

\section{Expected direction}

Unclear

Varies by location, extreme in some locations

Unknown, varies by location

Unknown, varies by location

Expected
magnitude

Moderate

High

Low

Moderate

\section{Ways to reduce uncertainty/bias}

Use electrical grid model with higher time resolution (e.g., seasonal or time-of-day)

Run atmospheric model with source tagging

Develop/collect capacity factors by country

Develop emissions data and impact rates for individual power plants of Disease study and the accompanying uncertainties (Burnett et al., 2014). Along with uncertainties in the magnitude and shape of the IERs (being non-linear and with a steep slope at low concentrations and flattening at higher exposures) the health impact rates calculated here can change substantially with air pollution levels. Future versions of this model should be developed using air pollution transport models with the capability of tracking air pollution from sources as it crosses political boundaries, so health impacts can be assigned to source countries and regions; future versions could also track the impacts of trade and movement of economic activities (Zhang et al., 2017).

The country-level metrics also treat all electrical generation and transport within a country as one uniform, monolithic fleet, without accounting for substantial variability in the health impacts of emissions within a country (Buonocore et al., 2014; Heo et al., 2016; Penn et al., 2017). This means that the benefits of any new renewable energy generation within one country are treated similarly-same for benefits of all transportation 
improvements in a given country-even if the use is geographically clustered in certain regions in a country (e.g., a rail network in a dense urban corridor), or if they are used at different times of day (e.g., solar energy) or different seasons (e.g., wind energy). Within a country, the health impacts of a given emission can vary substantially by geography and the spatial relationship between the location of an air pollution source and areas with large populations, such as power plants in the vicinity of urban centers (Buonocore et al., 2014; Heo et al., 2016; Penn et al., 2017). Timing and seasonality of emissions can affect their impact, due to daily and annual changes in the mixing height of the lower atmosphere and other meteorological factors, as well as changing energy demand (Buonocore et al., 2014; Heo et al., 2016; Penn et al., 2017). There is also variability in the emissions rate of individual sources that is not accounted for by this model (SilerEvans et al., 2012; Buonocore et al., 2014). This means that the ability of impact opportunity models to differentiate between projects in different regions of a given country, or between projects that may have important daily or seasonal patterns can be improved.

For example, if this framework is used to estimate the benefits of improvements in the efficiency of freight vehicles, the model will not be able to isolate old and high-emission heavy-duty diesel trucks from the rest of the vehicle fleet, which may bias the results downward. Similarly, this model cannot differentiate between the efficiency improvement being implemented widespread across the country, and, for example, a targeted upgrade on vehicles mainly used for inter-city transportation of goods. This may bias results upward if inter-city driving does not represent typical driving conditions in the country, or if the highways used for inter-city travel are not the location of most vehicular traffic, which would be the case if the majority of the traffic was within urban areas. If this framework is used to estimate the benefits of installing renewable energy, it will miss various nuances, such as which power plants are displaced and when and where these plants are located, substantially affecting the apparent benefits of renewable energy (Li et al., 2017; Buonocore et al., 2015; Buonocore et al., 2016; Wiser et al., 2017). Additionally, the model results are susceptible to uncertainties in exposure-response functions, especially the estimation of effects at very low concentrations, very high concentrations, and in countries where there have not been long-term studies of the health effects of air pollution exposure (Burnett et al., 2014).

The framework for renewable energy uses installed capacity of renewable energy by type, which is a limited proxy measure for energy generated. Capacity factors can vary depending on a combination of factors, including turbine design and height, specific location of installation, and operational decisions made by the operator of the wind turbine and the local electric utility. Data on actual electricity generation by location of turbine and turbine manufacturer would reduce this uncertainty, but that data is not currently made available publicly.

Future iterations of this methodology can provide more geographic and temporal resolution. The data sources for $\mathrm{CO}_{2}$ emissions are updated yearly and available for all countries, however, the air pollution emissions are typically revised with longer time periods between versions, typically every five years, and health outcomes are usually evaluated on the basis of longterm exposure. Updating all of these underlying metrics on a yearly basis would keep this system up-to-date with changes in the vehicle fleet and the electrical grid mix. Keeping this model and set of metrics up-to-date would be possible. As the existing data sources and modeling come largely from the International Energy Agency and the European Commission, this methodology could fit under those existing frameworks, or other intergovernmental and international organizations, such as the United
Nations or the World Bank. As these models are designed to measure the benefits of publicly-traded companies, this model could also be updated by a non-governmental organization similar to those that manage the standards for carbon offsets, consulting groups, or others active in sustainable investing.

The results of our statistical analysis of the relationship between the $\mathrm{CO}_{2}$ emissions and health metrics indicates that the relationship between $\mathrm{CO}_{2}$ emissions and health impacts is not a simple one, and robust updates to this methodology may require full atmospheric modeling and health impact analysis. Additional improvements could include pollutant-tracking and assignment to sources - this would allow for accounting of trans-boundary pollution and remove a source of error from this model. The model could be further improved by the inclusion of more detailed economic models of electricity generation and of transportation to better estimate which sources would be displaced by deployment of renewable energy or cleaner and more efficient transportation technologies, although the costs for highly detailed analysis might be prohibitive. When data on vehicle-km, ton-km, or passenger-km traveled becomes available globally, that can be added as well. Future iterations of this methodology could also be directly tied to SDG indicators, targets, and goals, include the full life cycle of both positive and negative impacts, link to other SDG targets, and explicitly reference planetary boundaries (O’Neill et al., 2018).

Strengths of country-level model. The methodology and set of metrics developed here is, to our knowledge, the first that provides global, country-level, metrics to estimate the public health gains and $\mathrm{CO}_{2}$ emissions reductions that could result from changes to electricity generation or the transportation infrastructure of a given country. These metrics were developed using existing data and model results, provide information useful for policy and investment decision-making around electricity and transportation, and add to the existing evidence that location is an extremely important driver of benefits of changes to electricity and transportation (Vörösmarty et al., 2018; Barbose et al., 2016; Wiser et al., 2017; Millstein et al., 2017; Buonocore et al., 2016; Buonocore et al., 2015). Despite the limitations of this current model framework, this information has value for policy and investment decision-making. This methodology also provides a "scaffolding" to which additional enhancements can be made to improve capture of physical and economic processes, detail, or other enhancements.

The methodology and set of metrics can provide a first stage in determining where investment in the use of energy efficiency technologies and renewable energy might have substantial climate and health benefits. These metrics can highlight countries where the most benefit can be achieved from installing renewable energy, making electrical generation or consumption more efficient, improving fuel economy for existing vehicles, and shifting transportation towards low- to zero-emission modes of transportation. This set of metrics can be used alongside other considerations that may go into an investment decision, including environmental and energy policies active or in consideration in the countries where a company is active, information on the social environment of each company, or other types of information independent of the benefits to climate, air pollution emissions, and health if investments were made.

This system of metrics does not preclude the use of other more detailed scientific analyses or tools to determine impact, such as the application of detailed electrical grid modeling and atmospheric chemistry and transport modeling. It does, however, make explicit that activities of renewable energy companies and transportation companies can have large positive impacts. These 
metrics also provide some information on which companies contribute to the SDGs and can count as "sustainable" for their purposes-economically, environmentally and socially. It also does so in a way that is informed by science, but without introducing a prohibitive level of complexity. A system of metrics that is overly complex and cumbersome could raise insurmountable barriers to entry for results-oriented companies and investors (Vörösmarty et al., 2018). Reducing barriers to adoption is important for meeting the goals of the Paris Agreement in particular. Support from all sectors of the economy will be crucial to overcome the "committed" carbon emissions from the expected lifetime of existing power plants and other fossil fuel infrastructure, since we will most likely need to decommission fossil-fueled power plants before the end of their expected operational life (Pfeiffer et al., 2018; Smith et al., 2019).

The role of finance in the global economy makes investors pivotal to meeting the SDGs (Vörösmarty et al., 2018; United Nations Conference on Trade and Development, 2014). The metrics proposed here can provide a simple-to-implement and user-friendly method to better measure global progress toward SDGs and The Paris Agreement. These methods are grounded in and informed by scientific evidence that reflects important differences in geospatial context, and can be used by investors and other stakeholders to meaningfully measure progress toward the SDGs and meaningfully differentiate between companies in a way that could guide decision-making by investors, the companies themselves, and other stakeholder groups. Providing a system of metrics grounded in scientific evidence, could in turn encourage more companies to measure and disclose their contribution to the SDGs in a transparent and evidenced-based way. This can enable investors to deploy much needed capital toward supporting those companies that are making verifiable progress toward the SDGs.

\section{Data availability}

Some data used in this paper are publicly available from the International Energy Agency [https://www.iea.org/classicstats/ relateddatabases/worldenergystatisticsandbalances/]. Other data analyzed can be made available upon reasonable request to the authors.

Received: 16 August 2018; Accepted: 1 October 2019; Published online: 12 November 2019

\section{References}

Barbose G et al. (2016) A retrospective analysis of benefits and impacts of U.S. renewable portfolio standards. Energy Policy 96(C):645-660

Buonocore JJ et al. (2015) Health and climate benefits of different energy-efficiency and renewable energy choices. Nat Clim Change 6(1):100-105

Buonocore JJ et al. (2016) Health and climate benefits of offshore wind facilities in the Mid- Atlantic United States. Environ Res Lett 11(7):1-11

Buonocore JJ et al. (2014) Using the community multiscale air quality (CMAQ) model to estimate public health impacts of PM2.5 from individual power plants. Environ Int 68(C):1-9

Burnett RT et al. (2014) An integrated risk function for estimating the global burden of disease attributable to ambient fine particulate matter exposure Environ Health Perspect 122(4):397-403

Crippa $\mathrm{M}$ et al. (2016) Forty years of improvements in European air quality: regional policy-industry interactions with global impacts. Atmos Chem Phys 16(6):3825-3841

Crippa $\mathrm{M}$ et al. (2018) Gridded emissions of air pollutants for the period 1970-2012 within EDGAR v4.3.2. Earth Syst Sci Data 10:1987-2013. https:// doi.org/10.5194/essd-10-1987-2018

Driscoll CT et al. (2015) US power plant carbon standards and clean air and health co-benefits. Nat Clim Change 5(6):535-540

FactSet (2017) FactSet. www.factset.com
Global Impact Investing Network (2014) Getting Started with IRIS. https://thegiin. org/research/publication/getting-started-with-iris

Global Reporting Initiative (2018) Annual Impact Investor Survey. https://thegiin. $\mathrm{org} /$ research/publication/annualsurvey2018

Global Reporting Initiative (2016) United Nations Global Compact World Business Council for Sustainable Development. SDG Compass. https://sdgcompass.org

Heo J, Adams PJ, Gao HO (2016) Public health costs of primary PM 2.5 and Inorganic PM 2.5 Precursor Emissions in the United States. Environ Sci Technol 50(11):6061-6070

Impact Management Project (2018) A Guide to Mapping the Impact of an Investment. https:/29kjwb3armds2g3gi4lq2sx1-wpengine.netdna-ssl.com/ wp-content/uploads/A-guide-to-mapping-the-impact-of-an-investment.pdf

International Energy Agency. World Energy Statistics and Balances. https://www. iea.org/statistics/. Accessed 2017

Lelieveld J et al. (2015) The contribution of outdoor air pollution sources to premature mortality on a global scale. Nature 525(7569):367-371. https://doi. org/10.1038/nature15371

Li M et al. (2017) Marginal emission factors considering renewables: a case study of the U.S. Midcontinent Independent System Operator (MISO) System. Environ Sci Technol 51(19):11215-11223

Lin J et al. (2014) China's international trade and air pollution in the United States. Proc Natl Acad Sci 111(5):1736-1741

Lin M et al. (2017) US surface ozone trends and extremes from 1980 to 2014: quantifying the roles of rising Asian emissions, domestic controls, wildfires, and climate. Atmos Chem Phys 17(4):2943-2970

MacNaughton P et al. (2018) Energy savings, emission reductions, and health cobenefits of the green building movement. J Exposure Sci Environ Epidemiol 28(4):307-318

McCollum DL et al. (2018) Connecting the sustainable development goals by their energy inter-linkages. Environ Res Lett 13(3):033006-033024

Menou V, Nishikawa L (2016) Toward sustainable impact through public markets.

Millstein D et al. (2017) The climate and air-quality benefits of wind and solar power in the United States. Nat Energy 2(9):17134

National Aeronautics and Space Administration, Socioeconomic Data and Applications Center. https://sedac.ciesin.columbia.edu

Nerini FF et al. (2018) Mapping synergies and trade-offs between energy and the sustainable development Goals. Nat Energy 3:10-15

O'Neill DW et al. (2018) A good life for all within planetary boundaries. Nat Sustain 1:88

Penn SL et al. (2017) Estimating state-specific contributions to PM 2.5- and O 3 related health burden from residential combustion and electricity generating unit emissions in the United States. Environ Health Perspect 125(3):324-332

Pfeiffer A et al. (2018) Committed emissions from existing and planned power plants and asset stranding required to meet the Paris Agreement. Environ Res Lett 13(5):054019-12

Rekker SAC, Humphrey JE, O’Brien KR (2019) Do sustainability rating schemes capture climate goals? Bus Soc 31:000765031982576-36

Roth GA et al. (2018) Global, regional, and national age-sex-specific mortality for 282 causes of death in 195 countries and territories, 1980-2017: a systematic analysis for the Global Burden of Disease Study 2017. Lancet 392 (10159):1736-1788

Siler-Evans K, Azevedo IL, Morgan MG (2012) Marginal emissions factors for the U.S. electricity system. Environ Sci Technol 46(9):4742-4748

Smith CJ et al. (2019) Current fossil fuel infrastructure does not yet commit us to $1.5^{\circ} \mathrm{C}$ warming. Nat Commun 10

Trucost (2015) Trucost's valuation methodology. https://www.gabi-software.com/ fileadmin/GaBi_Databases/Thinkstep_Trucost_NCA_factors_methodology_ report.pdf

United Nations (2017) The Sustainable Development Goals Report 2017. https:// unstats.un.org/sdgs/files/report/2017/thesustainabledevelopmentgoalsreport2017. pdf

United Nations (2018) The Sustainable Development Goals Report. 1-40. https:// www.un.org/development/desa/publications/the-sustainable-developmentgoals-report-2018.html

United Nations Conference on Trade and Development (2014) World Invest Rep 2014:1-264

Vörösmarty CJ et al. (2018) Scientifically assess impacts of sustainable investments. Science 359(6375):523-525

Wiser R et al. (2017) Assessing the costs and benefits of US renewable portfolio standards. Environ Res Lett 12(9):094023-12

World Bank Group, Institute for Health Metrics and Evaluation (2016) The Cost of Air Pollution 1-122. http://documents.worldbank.org/curated/en/781521473177013155/ pdf/108141-REVISED-Cost-of-PollutionWebCORRECTEDfile.pdf

World Health Organization, Health Statistics and Information Systems. https:// www.who.int/healthinfo/en/. Accessed 2017

Zhang Q et al. (2017) Transboundary health impacts of transported global air pollution and international trade. Nature 543(7647):705-709 


\section{Acknowledgements}

The work was supported by a grant from UBS Asset Management. They have collaborated on this project and are listed as authors. We would like to thank Mike Welten for additional comments on this paper.

\section{Competing interests}

PK is employed by a pension fund that intends to apply the methodology developed here. DAK is employed by a data and analytics group that intends to apply the methodology here. The views expressed herein reflect those of the authors alone, are subject to change, and do not necessarily represent the views, policies, or positions of their employers. Industry and related data contained herein have been compiled in good faith from sources believed to be reliable. The remaining authors declare no competing interests.

\section{Additional information}

Supplementary information is available for this paper at https://doi.org/10.1057/s41599019-0336-4.

Correspondence and requests for materials should be addressed to J.J.B.

Reprints and permission information is available at http://www.nature.com/reprints
Publisher's note Springer Nature remains neutral with regard to jurisdictional claims in published maps and institutional affiliations.

(c) Open Access This article is licensed under a Creative Commons Attribution 4.0 International License, which permits use, sharing, adaptation, distribution and reproduction in any medium or format, as long as you give appropriate credit to the original author(s) and the source, provide a link to the Creative Commons license, and indicate if changes were made. The images or other third party material in this article are included in the article's Creative Commons license, unless indicated otherwise in a credit line to the material. If material is not included in the article's Creative Commons license and your intended use is not permitted by statutory regulation or exceeds the permitted use, you will need to obtain permission directly from the copyright holder. To view a copy of this license, visit http://creativecommons.org/ licenses/by/4.0/.

(C) The Author(s) 2019 